\title{
Clinical and prognostic differences between methicillin-resistant and methicillin- susceptible Staphylococcus aureus infective endocarditis
}

Carmen Hidalgo-Tenorio ${ }^{1 *}$ D, Juan Gálvez ${ }^{2}$, Francisco Javier Martínez-Marcos ${ }^{3}$, Antonio Plata-Ciezar ${ }^{4}$, Javier De La Torre-Lima ${ }^{5}$, Luis Eduardo López-Cortés ${ }^{2}$, Mariam Noureddine ${ }^{5}$, José M. Reguera ${ }^{4}$, David Vinuesa ${ }^{6}$, Maria Victoria García ${ }^{7}$, Guillermo Ojeda7, Rafael Luque ${ }^{8}$, José Manuel Lomas ${ }^{9}$, Jose Antonio Lepe ${ }^{8}$ and Arístides de Alarcón ${ }^{8}$

\begin{abstract}
Background: S. aureus (SA) infective endocarditis (IE) has a very high mortality, attributed to the age and comorbidities of patients, inadequate or delayed antibiotic treatment, and methicillin resistance, among other causes. The main study objective was to analyze epidemiological and clinical differences between IE by methicillinresistant versus methicillin-susceptible SA (MRSA vs. MSSA) and to examine prognostic factors for SA endocarditis, including methicillin resistance and vancomycin minimum inhibitory concentration (MIC) values $>1 \mu \mathrm{g} / \mathrm{mL}$ to MRSA.
\end{abstract}

Methods: Patients with SA endocarditis were consecutively and prospectively recruited from the Andalusia endocarditis cohort between 1984 and January 2017.

Results: We studied 437 patients with SA endocarditis, which was MRSA in 13.5\% of cases. A greater likelihood of history of COPD (OR 3.19; 95\% Cl 1.41-7.23), invasive procedures, or recognized infection focus in the 3 months before IE onset (OR 2.9; 95\% Cl 1.14-7.65) and of diagnostic delay (OR 3.94; 95\% Cl 1.64-9.5) was observed in patients with MRSA versus MSSA endocarditis.

The one-year mortality rate due to SA endocarditis was $44.3 \%$ and associated with decade of endocarditis onset (1985-1999) (OR 8.391; 95\% Cl (2.82-24.9); 2000-2009 (OR 6.4; 95\% Cl 2.92-14.06); active neoplasm (OR 6.63; 95\% Cl 1.7-25.5) and sepsis (OR 2.28; 95\% Cl 1.053-4.9). Methicillin resistance was not associated with higher IE-related mortality (49.7 vs. $43.1 \% ; p=0.32$ ).

Conclusion: MRSA IE is associated with COPD, previous invasive procedure or recognized infection focus, and nosocomial or healthcare-related origin. Methicillin resistance does not appear to be a decisive prognostic factor for SA IE.

Keywords: Endocarditis, Staphylococcus aureus, Vancomycin, Methicillin resistance

\footnotetext{
* Correspondence: chidalgo72@gmail.com

All participating doctors belong to Cardiovascular Infection Study Group of

the Andalusian Society of Infectious Diseases

${ }^{1}$ Department of Infectious Diseases, Hospital Universitario Virgen de las

Nieves, Av. de las Fuerzas Armadas n², 18014 Granada, Spain

Full list of author information is available at the end of the article
}

C The Author(s). 2020 Open Access This article is distributed under the terms of the Creative Commons Attribution 4.0 International License (http://creativecommons.org/licenses/by/4.0/), which permits unrestricted use, distribution, and reproduction in any medium, provided you give appropriate credit to the original author(s) and the source, provide a link to the Creative Commons license, and indicate if changes were made. The Creative Commons Public Domain Dedication waiver (http://creativecommons.org/publicdomain/zero/1.0/) applies to the data made available in this article, unless otherwise stated. 


\section{Background}

The incidence of infective endocarditis (IE) is low in industrialized countries (3-9 cases per 100,000 people-years) but has recently increased. This rise has been attributed to improvements in diagnostic methods, an increase in life expectancy, and a higher rate of instrumentalization (e.g., pacemaker and central venous catheter implantation, hemodialysis, etc.) in an increasingly aged and fragile population [1]. The most common type of IE is native valve endocarditis (largely mitral or aortic) [2]. Staphylococcus aureus (SA) is one of the most frequently involved bacteria $[3,4]$ and is associated with high morbidity and mortality rates due to its strong avidity for endothelial tissue, its capacity to produce endovascular infection, and its aggressive character $[5,6]$. A European study of hospitalized patients with bacteremia by SA reported a higher risk of 30-day mortality in those infected with methicillin-resistant S. aureus (MRSA) versus methicillin-susceptible $S$. aureus (MSSA) [OR of 1.8(95\%CI, 1.04 to 3.2)] [7]. Besides methicillin resistance, poor prognostic factors for bacteremia by SA include the presence of IE, comorbidities [8], inadequate antibiotic treatment [9], and a vancomycin minimum inhibitory concentration $(\mathrm{MIC})>1 \mu \mathrm{g} / \mathrm{mL}[10]$.

The objective of this study was to determine differences in epidemiological, clinical, and prognostic variables between MRSA versus MSSA IE and to analyze the prognostic value of vancomycin MIC > $1 \mu \mathrm{g} / \mathrm{mL}$ for MRSA.

\section{Methods}

We conducted a prospective, multicenter, longitudinal study of consecutive patients with IE hospitalized in eight hospitals of the Health Service of Andalusia (Spain) between 1984 and 2017. During this period, these hospitals prospectively enrolled a total of 2076 patients with IE from whom informed verbal consent to study participation was obtained. Ethics committee approved this procedure.

Among these patients, we prospectively enrolled in the present cohort the 437 patients with S. aureus endocarditis who met eligibility criteria. Information was prospectively gathered by attending physicians on epidemiological, clinical, analytical, and prognostic (mortality, relapse) data and on medical and surgical treatments. Heart surgery was available at five of the eight hospitals, to which candidates for surgery from the other three hospitals were transferred. Patients were followed up for 12 months after IE, monitoring clinical, analytical, and microbiological results. The EuroSCORE, logistic EUROSCORE, and modified Duke Criteria were calculated for all patients and included as study variables when they became incorporated into clinical practice, with the agreement of the endocarditis study group, as well as data on new antibiotics. There were no changes during the study period in the other study parameters, i.e., clinical, epidemiological, microbiological, analytical findings, duration of antibiotic therapy, performance of surgery, adequate antibiotic treatment (according to contemporary recommendations), or mortality data.

All information was treated in accordance with national legislation on personal data protection (Organic Law 15/1999, 13 December, of Personal Data Protection), and the study was approved by the ethics committee of the coordinating center (Hospital Universitario Virgen del Rocio, Seville).

\section{Inclusion criteria}

Inclusion criteria were: age $\geq 18$ years with "definite" or "possible" $S$. aureus IE according to modified Duke Criteria [11], which were retrospectively applied to patients enrolled before their publication.

\section{Definitions}

Previous valve disease included any rheumatic, congenital, degenerative/myxoid, or degenerative/calcified valve disease in the patient's clinical records.

History of invasive procedure or previous infection focus included previous dental manipulation (extraction or other invasive dental or maxillofacial technique) or invasive urinary or vascular procedure (e.g., central/peripheral catheterization) and/or the presence of a focus of infection (urinary, cutaneous, vascular, etc.) in the 3 months before the IE episode.

Central nervous system (CNS) symptoms included encephalopathy, meningitis, brain abscess, hemorrhagic or ischemic embolism, and transient stroke.

Acute kidney failure during hospitalization was defined by creatinine $>1.5 \mathrm{~mL}$ or $25 \%$ increase versus baseline.

The age-adjusted Charlson comorbidity index was used to estimate the 10-year life expectancy of our patients as a function of age and comorbidities [12], determined at admission to hospital for the endocarditis episode.

Surgical risk was estimated at admission in all patients using EuroSCORE I or II (European System for Cardiac Operative Risk Evaluation), which predicts early mortality after cardiac valve surgery $[13,14]$. We used both scores in order compare their capacity to predict the prognosis. In cases of IE between 1998 and 2017, this scale was calculated prospectively by the attending physician. In cases of IE before 1998, the EuroSCORE was calculated retrospectively from data in the clinical records.

IE relapse was defined by an episode of $S$. aureus endocarditis within 12 months of a first episode that had met cure criteria.

IE reinfection was defined by a second IE due to a microorganism other than SA during the follow-up year.

Mortality rates considered deaths for any cause during hospitalization or the first 30 days post-discharge (hospital mortality) as well as the IE-related mortality [e.g., 
heart failure due to valve dysfunction] and the non-IE-related mortality [e.g., cancer] at 1 year post-discharge.

Severe sepsis was defined by $\geq 2$ criteria of systemic inflammatory response syndrome with organ dysfunction; and Septic shock by sepsis with refractory hypotension and end-organ perfusion dysfunction despite adequate fluid resuscitation [15].

Early prosthetic IE was defined by onset during the first year post-surgery and Late prosthetic IE by onset after more than 1 year post-surgery [16].

Nosocomial IE was defined by symptom onset more than $48 \mathrm{~h}$ after hospital admission [17].

Healthcare-related IE was defined by symptom onset more after medical manipulation in the 3 months preceding the diagnosis (intravenous treatments, wound healing, hemodialysis, and stays at care home or assisted centers) [17].

The indication for surgery was initially assessed by the attending physician, based on universally accepted criteria at the time [18-20], and was confirmed by consensus of a multidisciplinary team that included attending physicians and heart surgeons, who also considered the quality of life, comorbidities, surgical prognosis, and life expectancy of patients.

Indications for surgery were divided into five groups: a) Surgery not indicated; b) Surgery indicated and performed without delay; c) Surgery indicated and performed with delay $>72 \mathrm{~h}$ in grade IV left ventricular failure (LVF) or delay > 1 week in progressive LVF; d) Surgery indicated but not performed for any cause (e.g., technical impossibility, neurological complication, death before surgery, patient refusal, etc.); and e) Surgery indicated but not proposed by the attending physician due to the condition of patients (e.g., comorbidity with low life expectancy, critical status, etc.).

Postponed surgery was defined by its performance after 1 month of hospitalization.

Methicillin resistance was defined by an inhibition halo for oxacillin of $\leq 10 \mathrm{~mm}$ or oxacillin $\mathrm{MIC} \geq 4 \mathrm{mg} / \mathrm{L}$. The E-test with oxacillin strip was used in some centers [21] and automated microdilution systems in others [22].

Adequacy of antibiotic treatment was defined by its accordance with antibiogram results and its recommendation for IE in clinical practice guidelines.

Diagnostic delay was defined by an interval of $\geq 7$ days between symptom onset and first hospital consultation.

\section{Statistical analysis}

In a descriptive analysis, central tendency and dispersion measures (mean, standard deviation, median, percentiles) were calculated for quantitative variables and absolute frequencies with 95\% confidence interval (CI) for qualitative variables. In bivariate analyses, prognostic, clinical, epidemiological, and therapeutic variables were compared between patients with MRSA IE versus MSSA IE, and mortality rates for SA endocarditis were compared with prognostic factors. The Student's t-test for independent samples was used for quantitative variables with a normal distribution and the Mann-Whitney $U$ test for those with non-normal distribution. Qualitative variables were analyzed using Pearson's or Fisher's chisquare test, as appropriate. The normality of variable distribution was checked with the Kolmogorov-Smirnov test. Two multivariate logistic regression models were developed according to Freeman's formula $\left[n=10^{*}(\mathrm{k}+\right.$ 1)] [23], one for differences between MRSA IE versus MSSA IE and the other for factors related to mortality in patients due to SA IE. The models included variables found to be statistically significant in bivariate analyses or considered clinically relevant. A stepwise procedure was used, considering an entry probability of 0.05 and exit probability of 0.10 . Goodness of fit was evaluated with the Hosmer-Lemeshow test. The regression model for differences between MRSA versus MSSA IE included the following variables: history of myocardiopathy, congenital heart disease, hemodialysis, chronic obstructive pulmonary disease (COPD); intravenous drug addiction; Charlson index; early prosthetic IE; perivalvular involvement diagnosed by echocardiography; previous invasive procedure or focus of infection; place of IE acquisition; interval between symptom onset and hospital admission; cutaneous manifestations (Osler's nodes, Janeway lesions); Duke vascular or embolic phenomena; and adequate treatment administration. The regression model for risk factors associated with mortality due to IE included: hospital where IE was treated, decade of IE onset, previous valve disease, early prosthetic IE, IE on pacemaker or defibrillator lead, IE on mitral valve, onset of IE as severe sepsis/septic shock, CNS involvement, kidney failure, heart failure, infectious osteoarticular involvement (arthritis/osteomyelitis), surgical risk (EuroSCORE, logistic EuroSCORE), heart surgery indicated without delay and performed during hospitalization, and surgery indicated but not performed. IBM SPSS Statistics 20.0 software was used for data analyses. The level of significance was 0.05 for all tests.

\section{Results}

Differences in epidemiological, clinical, and prognostic variables between MRSA versus MSSA IE

We included 378 patients with MSSA IE and 59 with MRSA IE from 1984 through January 2017 (15.8\% 1984-1999; 35.7\% 2000-2009, and 48.5\% 2010-2017).

According to bivariate analyses, the main epidemiological and clinical differences between IE by MRSA versus MSSA were age (62.5 vs. 58 years, $p=0.048)$; nosocomial acquisition (71.2 vs. $41.8 \%$; $p=0.001$ ); history of COPD (30.5 vs. $12.2 \% ; p=0.0001)$, elevated 
Charlson index (3 [1-4] vs. $2[0-3] ; p=0.006)$, history of previous invasive procedure or focus (79.7 vs. $57.1 \%$; $p=$ 0.001 ), and more frequent diagnostic delay (57.7 vs. $39.5 \%, p=0.05)$. In comparison to patients with MRSA IE, higher percentages of those with MSSA IE had congenital heart disease ( 7.1 vs. $0 \% ; p=0.037)$, were in a hemodialysis program (7.6 vs. $0 \% ; p=0.02)$, and had infectious perivalvular involvement during IE (28.3 vs. $15.3 \% ; p=0.043)$. The remaining results are listed in Tables 1 and 2.

With respect to outcomes, bivariate analysis showed a significantly longer hospitalization in patients with MRSA versus MSSA endocarditis (37 vs. 30 days; $p=$ $0.019)$ but no significant difference in mortality from IE at 1 year (49.1 vs. $43.7 \%, p=0.33$ ) or in the percentage of patients undergoing surgery (25.4 vs. $30.9 \% ; p=0.13$ ). Among the patients with MRSA IE, there was a larger percentage for whom surgery was indicated but not performed (18.6 vs. $10.1 \% ; p=0.05)$ and a higher relapse rate ( 10 vs. $3 \% ; p=0.05)$ (Table 3$)$.

The risk factors associated with MRSA in the multivariate analysis were: history of COPD (OR 3.19; 95\% CI 1.41-7.23), previous invasive procedure or recognized focus of infection in the three-month period before IE onset (OR 2.9; 95\% CI 1.14-7.65), and a delay of $\geq 7$ days between symptom onset and hospital admission (OR 3.94; 95\% CI 1.64-9.5) (Table 4).

\section{Prognostic value for IE of vancomycin MIC $>1 \mu \mathrm{g} / \mathrm{mL}$ for MRSA}

MIC values were determined by E-test in 37 (62.7\%) of MRSA cases and by microdilution in 22 (37.3\%). Vancomycin MICs for MRSA were available in $74.6 \%(44 / 59)$ of cases and were $>1 \mu \mathrm{g} / \mathrm{mL}$ in $38.6 \%$ (17/44). There were 4 relapses, observing $3(75 \%)$ in strains with MIC $>1 \mu \mathrm{g} / \mathrm{mL}$ and $1(25 \%)$ with MIC $\leq 1(p=0.7)$. The Mortality attributable to MRSA IE in hospital or during the first 30 days post-discharge was $49.1 \%$ (29/59) of which Vancomycin AUC:CMI was available in 18 patients. The hospital mortality rate was $61.1 \%(11 / 18)$ in strains with MIC $\leq 1 \mu \mathrm{g} / \mathrm{mL}$ versus $38.8 \%$ (7/18) with MIC $>1 \mu \mathrm{g} / \mathrm{mL}$, also a non-significant difference $(p=0.847)$.

\section{Risk factors associated with mortality from SA}

During the hospital stay or within 30 days post-discharge, $182(44.8 \%)$ patients died from SA endocarditis-specific mortality. The mortality rate was $56.9 \%$ (37/65) in 1985-1999; $53.8 \%(78 / 145)$ in $2000-2009$; and $34.2 \%(67 / 196)$ in 2010 2017. During the one-year follow-up, 13 (2.9\%) died from a cause other than IE, 6 (1.4\%) died from a new IE episode due to a resistant strain, and $16(3.7 \%)$ were lost to the follow-up. Data were available on the treatment of 378 patients $(86.5 \%)$, and $342(90 \%)$ of these received adequate initial antibiotic treatment according to the antibiogram and clinical practice guidelines.

The mortality from SA in our cohort was associated in bivariate analyses with: the decade of endocarditis onset (1985-1999: mortality rate of $20.3 \%$ (37/182) vs. survival rate of $12.5 \%(28 / 224), p=0.032$; 2000-2010: $42.8 \%$ (78/ $182)$ vs. $36.8 \%(67 / 224), p=0.007 ; 2010-2017$ : $36.8 \%$ $(67 / 182)$ vs $57.6 \%(129 / 224) ; p=0.0001)$; older age $(61.5$ vs. 56.4 years; $p=0.004)$; active neoplasm (11.2 vs. $5.8 \%$; $p=0.05)$; early prosthetic IE (9.4 vs. $4 \% ; p=0.028)$; mitral valve involvement (64.6 vs. $49.5 \%$; $p=0.03$ ); sepsis/ septic shock (46.7 vs. $27.8 \% ; p=0.0001)$; kidney failure during IE episode (52.2 vs. $33.9 \% ; p=0.0001)$; de novo heart failure (60.2 vs. $33.8 \%$; $p=0.0001)$; CNS involvement (encephalopathy 37.6 vs. $22.6 \%$; $p=0.006$; embolic stroke 29.6 vs. $18.7 \%$; $p=0.033$; meningitis $8.9 \%$ vs $5.8 \%$; $p=0.035$ ); high surgical risk (median EuroSCORE of 13 vs. 9; $p=0.0001$; median logistic EuroSCORE of 30.76 vs. 15.4; $p=0.0001$; and indication but non-performance of surgery ( 16.5 vs. $4.9 \% ; p=0.0001)$. MRSA itself did not emerge as a risk factor for mortality in our cohort (29\% vs. $11.8 \%, p=0.22)$ Protective factors were: IE on pacemaker lead or automatic implantable cardioverterdefibrillator (AICD) ( 2.8 vs. $12.9 \%$; $p=0.0001)$; osteoarticular spread of the infection (9.6 vs. $17.3 \% ; p=0.026$ ); heart surgery conducted when indicated without delay (23.1 vs. $36.2 \% ; p=0.004$ ). According to the multiple logistic regression analysis, poor prognostic factors for SA endocarditis were: decade of endocarditis onset in 19851999 (OR 8.391; 95\% CI (2.82-24.9) or 2000-2009 (OR 6.4; 95\% CI 2.92-14.06); active neoplasm (OR 6.63; 95\% CI 1.7-25.5); and sepsis/shock (OR 2.28; 95\% CI 1.0534.9) (Table 5).

\section{Discussion}

In this study of patients with $S$. aureus endocarditis, $13.5 \%$ were MRSA, all elderly men with multiple diseases, elevated Charlson index, and high surgical risk. Around half of the patients with MRSA had prior valve disease, which was rheumatic or degenerative in onethird of cases and of nosocomial origin or healthcarerelated in the remainder. The IE predominantly involved left-sided native valves (predominantly mitral valves) and less frequently cardiac devices, although such cases have become increasingly frequent. The mortality rate was very high, with around half of the patients dying from IE in hospital or within 30 days of their discharge. These data are similar to previous reports associating endocarditis with high morbidity and mortality rates and linking its acquisition to health care in up to $30 \%$ of cases [24]. These trends have been attributed to the increasing incidence of aortic valve disease in elderly populations, with a greater use of valve prostheses and intracardiac devices [25]. The main risk factors for in-hospital mortality in 
Table 1 Epidemiology and history of MRSA vs. MSSA endocarditis (bivariate analysis)

\begin{tabular}{|c|c|c|c|}
\hline & $\begin{array}{l}\text { MSSA IE } \\
N=378\end{array}$ & $\begin{array}{l}\text { MRSA IE } \\
N=59\end{array}$ & $p^{*}$ \\
\hline Mean age (yrs), ( \pm DS) & $\begin{array}{l}\text { 58.05. }( \pm \\
\text { 17.8) }\end{array}$ & 62.3. $( \pm 15)$ & 0.048 \\
\hline Females, n (\%) & $133(35.2)$ & $21(35.6)$ & 0.95 \\
\hline Males & $245(64.8)$ & $38(64.4)$ & \\
\hline Native IE, n (\%) & $295(78)$ & $44(74.6)$ & 0.55 \\
\hline Early prosthetic IE, n (\%) & $20(5.3)$ & $7(11.9)$ & 0.07 \\
\hline Late prosthetic IE, n (\%) & $39(10.3)$ & $4(6.7)$ & 0.39 \\
\hline IE on device (AICD, PMK), n (\%) & $34(8.9)$ & $5(8.4)$ & 0.89 \\
\hline \multicolumn{4}{|l|}{ Valve involved, n (\%) } \\
\hline - Mitral & $209(55.3)$ & $31(52.5)$ & 0.8 \\
\hline - Aortic & $129(34.1)$ & $16(27.1)$ & 0.34 \\
\hline - Mitro-aortic & $17(4.2)$ & 4 & 0.5 \\
\hline - Mitral, aortic, and tricuspid & $3(0.8)$ & 0 & 1 \\
\hline $\begin{array}{l}\text { - Mitral and tricuspid or } \\
\text { Aortic and tricuspid }\end{array}$ & $16(4.2)$ & $1(1.7)$ & 0.7 \\
\hline - Tricuspid & $46(12.1)$ & $7(11.8)$ & 0.99 \\
\hline - Pulmonary & $4(1.05)$ & $1(1.6)$ & 0.51 \\
\hline $\begin{array}{l}\text { - IE on interventricular } \\
\text { communication, n (\%) }\end{array}$ & $4(1.05)$ & 0 & 1 \\
\hline \multicolumn{4}{|l|}{ Acquisition setting, n (\%) } \\
\hline Community & $221(58.5)$ & $17(28.8)$ & \\
\hline Nosocomial & 128(33.9) & $37(62.7)$ & 0.0001 \\
\hline Healthcare-related & $29(7.7)$ & $5(8.5)$ & \\
\hline \multicolumn{4}{|c|}{ Decade of endocarditis onset, $\mathrm{n}(\%)$} \\
\hline 1985-1999 & $61(16.1)$ & $7(11.8)$ & 0.4 \\
\hline $2000-2009$ & $136(35.9)$ & $20(33.9)$ & 0.756 \\
\hline 2010-2017 & $180(47.6)$ & $32(54.2)$ & 0.344 \\
\hline \multicolumn{4}{|l|}{ History of: n (\%) } \\
\hline - previous IE & $18(4.8)$ & $7(11.9)$ & 0.64 \\
\hline $\begin{array}{l}\text { - valve disease on native } \\
\text { valve }\end{array}$ & $171(45.2)$ & $24(40.7)$ & 0.42 \\
\hline - Rheumatic & $51(13.5)$ & $7(11.9)$ & 0.68 \\
\hline $\begin{array}{l}\text { - Myxoid degeneration } \\
\text { and/or mitral prolapse }\end{array}$ & $26(6.9)$ & $3(5.1)$ & 0.78 \\
\hline - Degenerative/calcified & $58(15.3)$ & $10(16.9)$ & 0.8 \\
\hline - Congenital valve disease & $27(7.1)$ & 0 & 0.037 \\
\hline - Heart disease & $98(25.9)$ & $21(35.6)$ & 0.81 \\
\hline - Cardiomyopathy & $35(9.3)$ & $12(20.4)$ & 0.01 \\
\hline- COPD & $46(12.2)$ & 18(30.5) & 0.0001 \\
\hline - Diabetes Mellitus & $91(24.1)$ & $18(30.5)$ & 0.22 \\
\hline - Peptic ulcer & $5(1.3)$ & $3(5.1)$ & 0.12 \\
\hline - Arterial hypertension & $123(32.5)$ & $26(44.1)$ & 0.09 \\
\hline - Peripheral vascular disease & $21(5.6)$ & $6(10.2)$ & 0.24 \\
\hline - Stroke & $21(5.6)$ & $5(8.5)$ & 0.37 \\
\hline
\end{tabular}

Table 1 Epidemiology and history of MRSA vs. MSSA endocarditis (bivariate analysis) (Continued)

\begin{tabular}{|c|c|c|c|}
\hline & $\begin{array}{l}\text { MSSA IE } \\
N=378\end{array}$ & $\begin{array}{l}\text { MRSA IE } \\
N=59\end{array}$ & $p^{*}$ \\
\hline - Dementia & $6(1.6)$ & $2(3.4)$ & 0.3 \\
\hline - Active neoplasm & $30(7.9)$ & $6(10.2)$ & 0.61 \\
\hline - Colonic polyposis & $8(2.1)$ & $4(6.8)$ & 0.13 \\
\hline - Transplant $\left(^{*}\right)$ & $5(1.3)$ & 0 & 1 \\
\hline $\begin{array}{l}\text { - Chronic liver disease, } \\
\text { n (\%) }\end{array}$ & $49(12.9)$ & $6(10.2)$ & 0.54 \\
\hline - Child-Pugh A & $29(59.2)$ & $1(16.7)$ & \\
\hline - Child-Pugh B & $3(6.1)$ & $1(16.7)$ & 0.7 \\
\hline - Child-Pugh C & $3(6.1)$ & $1(16.7)$ & \\
\hline - Hemodialysis & $29(7.7)$ & 0 & 0.02 \\
\hline - Kidney failure & $80(21.2)$ & 11(18.6) & 0.6 \\
\hline -IVDA & $38(10.1)$ & 2(3.4) & 0.097 \\
\hline Charlson index, median (IQR) & $2(0-3)$ & $3(1-4)$ & 0.006 \\
\hline $\begin{array}{l}\text { Previous invasive procedure or } \\
\text { infection focus, } n(\%)\end{array}$ & $216(57.1)$ & $47(79.7)$ & 0.001 \\
\hline Vascular & $148(68.5)$ & $27(57.4)$ & 0.63 \\
\hline Urinary (catheter) & $7(3.2)$ & $4(8.5)$ & 0.08 \\
\hline Abdominal & $3(1.4)$ & $2(4.3)$ & 0.19 \\
\hline Dental & $5(2.3)$ & 0 & 1 \\
\hline Locomotor & $6(2.8)$ & $3(6.4)$ & 0.17 \\
\hline
\end{tabular}

COPD Chronic Obstructive Pulmonary Disease; IVDA intravenous drug addiction; Kidney failure: creatinine clearance increase of $>1.5 \mathrm{~mL} / \mathrm{min}$ or $25 \%$ versus baseline. Transplant (*): 3 kidney, 1 heart, 1 hematopoietic progenitor

patients with IE were recently reported to be $S A$ etiology, high Charlson index score, and EuroSCORE II $\geq 9$ [26]. In our patients with MRSA endocarditis, surgery was considered appropriate in 41 patients but was only carried out in 15 (36.5\%), being ruled out in 7 patients due to their poor clinical status. The percentage of patients who receive surgery when indicated ranged between 15 and $45 \%$ in a recent review of $S$. aureus and endocarditis; this review reported contradictory data on the benefits of early surgery, observing that surgery was sometimes delayed for weeks or months beyond the end of antibiotic IE treatment to correct the valve damage responsible for heart failure [27].

The main differences between MRSA and MSSA endocarditis in our study population was the greater frequency of the former in patients with COPD and its association with a longer interval between symptom onset and hospital admission ( $\geq 7$ days in around $60 \%$ of cases). One reason may be the higher MRSA colonization rate in patients with COPD due to their repeated contact with the health care system [28]. The exacerbation of COPD, mainly during the winter, is one of the principal causes of hospitalization and is often responsible for iatrogenesis, adverse effects, and functional 
Table 2 Comparison of clinical and echocardiographic findings between MRSA versus MSSA endocarditis (bivariate analysis)

\begin{tabular}{|c|c|c|c|}
\hline & $\begin{array}{l}\text { MSSA IE } \\
N=378\end{array}$ & $\begin{array}{l}\text { MRSA IE } \\
N=59\end{array}$ & $p^{*}$ \\
\hline $\begin{array}{l}\text { Findings }<1 \text { week before } \\
\text { hospitalization, } \mathrm{n}(\%)\end{array}$ & $\begin{array}{l}212 / 355 \\
(59.7)\end{array}$ & $\begin{array}{l}22 / 52 \\
(42.3)\end{array}$ & 0.051 \\
\hline \multicolumn{4}{|l|}{ Clinical n (\%) } \\
\hline - Fever & $365(96.6)$ & $55(93.2)$ & 0.251 \\
\hline - Dyspnea & $174(46)$ & $31(52.5)$ & 0.361 \\
\hline - Constitutional syndrome & $81(21.4)$ & 11(18.6) & 0.689 \\
\hline - Murmur & 199(52.6) & $30(50.8)$ & 0.822 \\
\hline - Hepatomegaly & $66(17.4)$ & $8(13.6)$ & 0.420 \\
\hline - Splenomegaly & $48(12.7)$ & $9(15.3)$ & 0.615 \\
\hline - CNS & 156(41.3) & 18(30.5) & 0.116 \\
\hline Encephalopathy & $76(20.1)$ & $9(15.3)$ & 0.4 \\
\hline Meningitis & $20(5.3)$ & $1(1.69)$ & 0.3 \\
\hline Abscess & $6(1.6)$ & 0 & 1 \\
\hline $\begin{array}{l}\text { Embolic non-hemorrhagic } \\
\text { stroke }\end{array}$ & $62(16.4)$ & $7(11.9)$ & 0.43 \\
\hline Embolic hemorrhagic stroke & $11(2.9)$ & $2(3.39)$ & 0.68 \\
\hline $\begin{array}{l}\text { Hemorrhagic stroke with no } \\
\text { previous Embolism }\end{array}$ & $22(5.8)$ & $2(3.39)$ & 0.75 \\
\hline - Renal embolism & $6(1.6)$ & 0 & 1 \\
\hline - Spleen embolism & $22(5.8)$ & $5(8.5)$ & 0.387 \\
\hline - Large vessel embolism & $30(7.9)$ & $5(8.5)$ & 0.799 \\
\hline - Pulmonary embolism & $27(7.1)$ & $8(13.6)$ & 0.119 \\
\hline - Roth's spots & $13(3.4)$ & 0 & 0.228 \\
\hline - Conjunctival hemorrhage & 15(3.9) & 0 & 0.230 \\
\hline - Endophthalmitis & 0 & $1(1.7)$ & 0.127 \\
\hline - Cutaneous manifestation & $108(28.6)$ & $11(18.6)$ & 0.093 \\
\hline - Petechiae & $80(21.2)$ & $7(11.9)$ & 0.115 \\
\hline - Janeway lesions & $53(14)$ & $3(5.1)$ & 0.054 \\
\hline - Osler's nodes & $61(16.1)$ & $4(6.8)$ & 0.057 \\
\hline - Splinter hemorrhage & $43(11.4)$ & $5(8.5)$ & 0.496 \\
\hline $\begin{array}{l}\text { - Duke vascular or embolic } \\
\text { phenomena }\end{array}$ & $120(31.7)$ & $12(20.4)$ & 0.072 \\
\hline $\begin{array}{l}\text { - Duke immunological } \\
\text { phenomena }\end{array}$ & $29(7.7)$ & $1(1.7)$ & 0.099 \\
\hline - Osteoarticular involvement & $52(13.8)$ & $8(13.6)$ & 0.98 \\
\hline $\begin{array}{l}\text { - Acute kidney failure } \\
\text { during hospitalization }\end{array}$ & $159(42)$ & $22(37.3)$ & 0.469 \\
\hline - Heart failure & $171(45.2)$ & $25(42.4)$ & 0.643 \\
\hline Grade III-IV & $90(23.8)$ & $18(30.5)$ & 0.3 \\
\hline - Severe sepsis/Septic shock & $97(25.7)$ & $14(23.7)$ & 0.751 \\
\hline - Acute pulmonary edema & 93(24.6) & $17(28.8)$ & 0.446 \\
\hline \multicolumn{4}{|l|}{ Echocardiographic findings, $\mathrm{n}(\%)$ ** } \\
\hline - Diagnostic data & $336(88.9)$ & 49(83.1) & 0.34 \\
\hline - Vegetation & 249(65.9) & $43(72.9)$ & 0.615 \\
\hline - Perivalvular lesion & $107(28.3)$ & $9(15.3)$ & 0.043 \\
\hline
\end{tabular}

Table 2 Comparison of clinical and echocardiographic findings between MRSA versus MSSA endocarditis (bivariate analysis) (Continued)

\begin{tabular}{llll}
\hline & MSSA IE & MRSA IE & $p^{*}$ \\
& $N=378$ & $N=59$ & \\
\hline - Pseudoaneurysm & $14(3.7)$ & $1(1.7)$ & 0.7 \\
- Fistula in valvular system & $8(2.1)$ & $2(3.4)$ & 0.63 \\
$\begin{array}{l}\text { - Valvular system rupture or } \\
\text { perforation }\end{array}$ & $63(16.7)$ & $6(10.2)$ & 0.226 \\
$\begin{array}{l}\text { - Prosthesis dehiscence or } \\
\text { dysfunction }\end{array}$ & $23(6.1)$ & $5(8.5)$ & 0.39 \\
$\begin{array}{l}\text { - Pericardial effusion } \\
\text { IE classification, n(\%) }\end{array}$ & $14(3.7)$ & $2(4.4)$ & 1 \\
$\begin{array}{l}\text { Possible } \\
\text { Definite }\end{array}$ & $25(6.6)$ & $7(11.9)$ & \\
\hline
\end{tabular}

$\left.{ }^{* *}\right)$ Transthoracic Echocardiogram was obtained in $94.9 \%$ of patients with MRSA IE and transesophageal echocardiogram in $54.2 \%$. Transthoracic echocardiogram was obtained in $96.3 \%$ of patients with MSSA IE and transesophageal echocardiogram in $56.3 \%$

decline [29]. This may be an important reason for the delay in hospital care.

Previous invasive procedures and/or infectious foci were also more frequent in the patients with MRSA versus MSSA IE, with $70 \%$ of the former being of nosocomial origin. There were no significant differences between MRSA and MSSA IE in surgical intervention or mortality rates or in the receipt of adequate antibiotic therapy. Many authors have associated mortality due to SA with methicillin resistance. A recent meta-analysis of 62 studies of bacteremia (13 of IE alone) found a higher mortality risk for MRSA versus MSSA, with an OR of 2.65 (95\% CI, 1.46-4.80) [6]. It should be noted that most published studies on the role of methicillin resistance in the prognosis of $S$. aureus bacteremia do not include cases of endocarditis. It should also be acknowledged that the prognosis of IE is influenced by numerous factors; therefore, the added prognostic value of data on methicillin resistance and vancomycin MIC may be limited. The association of methicillin resistance with higher treatment failure rate in our cohort did not reach statistical significance, possibly due to the low relapse rate after IE treatment with prolonged antimicrobial therapy and frequent removal of the infection focus (heart surgery).

The importance of vancomycin susceptibility in methicillin-resistant and even methicillin-susceptible strains is controversial. After initial studies described worse outcomes for methicillin-resistant strains with high vancomycin MIC values $[9,30]$, various metaanalyses on the relevance of MIC in SA infections have associated values $\geq 2 \mu \mathrm{g} / \mathrm{mL}$ with higher mortality (OR 1.72; 95\% CI: $1.34-2.21$ ) and values $\geq 1.5 \mu \mathrm{g} / \mathrm{mL}$ with 
Table 3 Prognosis, adequacy of antibiotic therapy, and surgical outcomes in MRSA versus MSSA IE

\begin{tabular}{|c|c|c|c|}
\hline & MSSA IE $N=378$ & MRSA IE $N=59$ & $p^{*}$ \\
\hline Mortality at 1 year, $\mathrm{n}(\%)$ & $165(43.7)$ & $29(49.1)$ & 0.32 \\
\hline Mortality at 1 year not related to IE, $\mathrm{n}(\%)$ & $13(4.2)$ & 0 & 0.316 \\
\hline Mortality attributable to SA IE in hospital or during the first 30 days post-discharge, n (\%) & $152(40.2)$ & $29(49.1)$ & 0.222 \\
\hline \multicolumn{4}{|l|}{ Mortality attributable to IE in the following periods, n (\%) } \\
\hline 1984-1999 & $35(23)$ & $2(6.99)$ & 0.122 \\
\hline 2000-2009 & $64(42.1)$ & $12(41.4)$ & 0.215 \\
\hline 2010-2017 & $52(34.2)$ & $15(51.7)$ & 0.062 \\
\hline Reinfection, n (\%) & $6(1.5)$ & 0 & 0.316 \\
\hline IE relapse, n (\%) & $8(3.1)$ & $4(6.8)$ & 0.053 \\
\hline Adequacy of antibiotic therapy, $\mathrm{n}(\%)$ & 302/332 (91) & $40 / 46(87)$ & 0.085 \\
\hline Days of antibiotic therapy, median (IQR) & $32(19-44.5)$ & $41(20-62)$ & 0.219 \\
\hline Hospital stay (days), median (IQR) & $30(16-47)$ & $37(21-58)$ & 0.019 \\
\hline Surgery not indicated n (\%) & $128(33.9)$ & $18(30.5)$ & 0.189 \\
\hline Surgical treatment on admission, $\mathrm{n}(\%)$ & $127(32)$ & $15(25.4)$ & 0.13 \\
\hline Postponed surgery after discharge, $\mathrm{n}(\%)$ & $8(2.1)$ & 0 & 0.61 \\
\hline Surgery indicated and conducted without delay, n (\%) & $117(30.9)$ & $12(20.3)$ & 0.11 \\
\hline Surgery indicated and conducted with delay: > $72 \mathrm{~h}$ in left ventricular failure grade IV, $\mathrm{n}(\%)$ & $9(2.4)$ & $3(5.1)$ & 0.21 \\
\hline Surgery indicated and not conducted in hospital, $\mathrm{n}(\%)$ & $88(23.3)$ & $18(30.5)$ & 0.23 \\
\hline Surgery indicated but not conducted, n (\%) & $38(10.1)$ & $11(18.6)$ & 0.052 \\
\hline Surgery indicated but not conducted due to poor clinical status, n (\%) & $50(13.2)$ & $7(11.86)$ & 0.7 \\
\hline
\end{tabular}

Table 4 Results of the multivariate analysis of MRSA vs. MSSA endocarditis

\begin{tabular}{lll}
\hline & OR & 95\% Cl \\
\hline COPD & $\mathbf{3 . 1 9}$ & $\mathbf{1 . 4 - 7 . 2 3}$ \\
Early prosthetic IE & 2.13 & $0.69-3.98$ \\
Nosocomial or healthcare-related IE & 1.64 & $0.69-3.99$ \\
Cardiomyopathy & 2.22 & $0.84-5.91$ \\
Congenital disease & 0 & 0 \\
Arterial hypertension & 1.16 & $0.54-2.49$ \\
Hemodialysis & 0 & 0 \\
Charlson's index & 0.92 & $0.776-1.095$ \\
Invasive procedure and/or focus of infection & $\mathbf{2 . 9 5}$ & $\mathbf{1 . 1 4 - 7 . 6 5}$ \\
IVDA & 1.18 & $0.21-6.66$ \\
Osler's node & 0.73 & $0.163-3.24$ \\
Janeway lesion & 0.737 & $0.137-3.96$ \\
Duke vascular or embolic phenomena & 0.19 & $0.716-5.493$ \\
Delay in hospital care & $\mathbf{3 . 9 4}$ & $\mathbf{1 . 6 4 - 9 . 4 6 8}$ \\
Echocardiography with perivalvular lesion & 0.395 & $0.15-1.03$ \\
Adequate antibiotic therapy & 0.532 & $0.214-1.321$ \\
\hline COPD Chronic Obstructive Pulmonary Disease; IVDA intravenous & \\
drug addiction & &
\end{tabular}

treatment failure (OR 2.69; 95\% CI:1.60-4.51) [10]. These associations have been observed not only in MRSA but also in Staphylococcus coagulase-negative IE with vancomycin MIC $\geq 2 \mu \mathrm{g} / \mathrm{mL}$ [31] and even in IE [32] and bacteremia due to MSSA with MIC $\geq 1.5 \mu \mathrm{g} /$ $\mathrm{mL}$, which was associated with a higher risk of complicated bacteremia [33, 34]. In contrast, a longitudinal, prospective, multicenter study of MRSA endocarditis found no association of vancomycin $\mathrm{MIC} \geq 1.5 \mu \mathrm{g} / \mathrm{mL}$ with higher mortality, although it was related to a greater persistence of bacteremia and a higher frequency of sepsis/septic shock, peripheral embolism, and arthritis/osteomyelitis [35]. Likewise, a study on beta-lactamtreated left-sided MSSA endocarditis found no relationship between vancomycin MIC and mortality or microorganism virulence [36].

The mortality rate of $S$. aureus endocarditis was very high in our cohort, despite the receipt of antibiotic treatment that accorded with antibiogram results and was recommended in available clinical practice guidelines by $90 \%$ of the patients. Active neoplasm, sepsis/shock, and decade of endocarditis onset (1985-1999 or 2000-2009 vs. 2010-2017) emerged as poor prognostic factors, but early surgery (within first 2 weeks) did not appear to influence the prognosis. A recent multicenter, longitudinal, observational study of SA IE $(n=213$ cases $)$ reported a mortality rate of 
Table 5 Risk factors associated with mortality in SA endocarditis. Results of bivariate and multivariate analyses

\begin{tabular}{|c|c|c|c|c|}
\hline & Death $N=182$ & Survivors $N=224$ & $p^{*}$ & OR $(95 \% \mathrm{Cl}) ; \mathrm{p}^{*}$ \\
\hline Age (yrs), media ( \pm DS) & $61.5( \pm 16.83)$ & $56.4( \pm 17.75)$ & 0.004 & $1.02(0.997-1.042) ; 0.09$ \\
\hline Females, n (\%) & $66(36.3)$ & $76(33.9)$ & 0.62 & \\
\hline Native IE, n (\%) & 146(80.2) & 168(75) & 0.21 & \\
\hline Early prosthetic IE, n (\%) & $17(9.4)$ & $9(4)$ & 0.028 & $1.307(0.395-4.328) ; 0.661$ \\
\hline Late prosthetic IE, n (\%) & $22(12.2)$ & 20(8.9) & 0.29 & \\
\hline IE in devices (AICD, PMK), n (\%) & $5(2.8)$ & $29(12.9)$ & 0.0001 & $0.34(0.06-2.12) ; 0.252$ \\
\hline \multicolumn{5}{|l|}{ Affected valve, n (\%) } \\
\hline Mitral & $115(64.6)$ & $110(49.5)$ & 0.03 & $1.456(0.742-2.86) ; 0.274$ \\
\hline Aortic & $61(34.1)$ & $73(32.9)$ & 0.83 & \\
\hline Tricuspid & $21(11.7)$ & $30(13.5)$ & 0.59 & \\
\hline Pulmonary & $4(2.2)$ & 0 & 0.025 & \\
\hline Mitral and aortic & $9(4.9)$ & $12(5.3)$ & 0.91 & \\
\hline Mitral, aortic, and tricuspid & $2(1.1)$ & $1(0.04)$ & 0.59 & \\
\hline Mitral and tricuspid & $10(5.5)$ & $6(2.6)$ & 0.19 & \\
\hline Community acquisition setting, $\mathrm{n}(\%)$ & $93(51.1)$ & $129(57.6)$ & 0.181 & \\
\hline \multicolumn{5}{|l|}{ Decade of endocarditis onset, $\mathrm{n}(\%)$} \\
\hline 1985-1999 & $37(20.3)$ & $28(12.5)$ & 0.0032 & $8.391(2.82-24.95) ; 0.0001$ \\
\hline 2000-2009 & $78(42.9)$ & $67(29.9)$ & 0.007 & $6.41(2.921-14.06) ; 0.0001$ \\
\hline 2010-2017 & $67(36.8)$ & $129(57.6)$ & 0.0001 & \\
\hline \multicolumn{5}{|l|}{ Hospital where IE was treated, n (\%) } \\
\hline HUVR, $(n=156)$ & $75(41.2)$ & $81(36.2)$ & & \\
\hline HUVM, $(n=47)$ & $18(9.9)$ & $29(12.9)$ & & \\
\hline HURM, $(n=63)$ & $28(15.4)$ & $35(15.6)$ & & \\
\hline HUW, $(n=54)$ & $24(13.2)$ & $30(11.4)$ & 0.189 & \\
\hline $\mathrm{HCS},(n=18)$ & $8(4.4)$ & $10(4.5)$ & & \\
\hline HJRJ, $(n=23)$ & $15(8.2)$ & $8(3.6)$ & & \\
\hline HUSC, $(n=11)$ & $5(2.7)$ & $6(2.7)$ & & \\
\hline HUVN, $(n=34)$ & $9(4.9)$ & $25(11.2)$ & & \\
\hline \multicolumn{5}{|l|}{ History of, n (\%): } \\
\hline - Previous IE & $11(4.9)$ & 12(36.6) & 0.473 & \\
\hline - Previous valve disease & $90(51.7)$ & $92(42.2)$ & 0.060 & $0.846(0.437-1.64) ; 0.621$ \\
\hline Rheumatic & $33(19.4)$ & $22(10.2)$ & 0.011 & \\
\hline Myxoid & $8(4.7)$ & 20(9.3) & 0.085 & \\
\hline Degenerative/calcified & $36(21.2)$ & $27(12.6)$ & 0.023 & \\
\hline Congenital & $6(3.5)$ & $16(7.4)$ & 0.101 & \\
\hline - Heart disease & $110(60.4)$ & $123(54.9)$ & 0.288 & \\
\hline - Acute myocardial infarction previous to IE & $8(4.4)$ & $12(5.4)$ & 0.674 & \\
\hline - Auricular fibrillation & 20(11.1) & $17(7.6)$ & 0.223 & \\
\hline - Cardiomyopathy & $17(9.4)$ & 26(11.6) & 0.484 & \\
\hline$-\mathrm{COPD}$ & $31(17.2)$ & $27(12.1)$ & 0.141 & \\
\hline - Diabetes mellitus & $49(27.2)$ & $52(23.2)$ & 0.355 & \\
\hline - Hypertension & $56(30.8)$ & $84(37.7)$ & 0.146 & \\
\hline - Peripheral vascular disease & $9(5)$ & $16(7.1)$ & 0.336 & \\
\hline - Stroke & $14(7.8)$ & $12(5.4)$ & 0.149 & \\
\hline
\end{tabular}


Table 5 Risk factors associated with mortality in SA endocarditis. Results of bivariate and multivariate analyses (Continued)

\begin{tabular}{|c|c|c|c|c|}
\hline & Death $N=182$ & Survivors $N=224$ & $p^{*}$ & OR $(95 \% \mathrm{Cl}) ; \mathrm{p}^{*}$ \\
\hline - Dementia & $5(2.8)$ & $2(0.9)$ & 0.25 & \\
\hline - Active neoplasm & $20(11.2)$ & $13(5.8)$ & 0.051 & $6.627(1.72-25.53) ; 0.006$ \\
\hline - Kidney failure & $38(21)$ & $47(21)$ & 0.998 & \\
\hline - Hemodialysis & $12(6.6)$ & $16(7)$ & 0.86 & \\
\hline - Liver disease & $22(12.2)$ & $29(12.9)$ & 0.811 & \\
\hline - Child-Pugh A & 10() & 18() & & \\
\hline - Child-Pugh B & 50 & 40 & 0.553 & \\
\hline - Child-Pugh C & $2(1.1)$ & $2(0.9)$ & & \\
\hline - HIV infection & $4(2.2)$ & $7(3.2)$ & 0.76 & \\
\hline - IVDA & $15(8.3)$ & $23(10.3)$ & 0.508 & \\
\hline -Transplant $(*)$ & 0 & $5(2.2)$ & 0.068 & \\
\hline Charlson's index, median (IQR) & $4(2-5)$ & $2(0.9-4)$ & 0.084 & \\
\hline History of invasive procedure or previous focus, n (\%) & $115(63.2)$ & $133(59.6)$ & 0.46 & \\
\hline Going to hospital during first 7 days of symptom onset, $\mathrm{n}(\%)$ & $110(63.6)$ & $105(51.5)$ & 0.018 & \\
\hline Adequate antibiotic treatment, $\mathrm{n}(\%)$ & 139(76.4) & $183(81.6$ & 0.362 & \\
\hline Severe sepsis/septic shock, n (\%) & $85(46.7)$ & $62(27.8)$ & 0.0001 & $2.286(1.053-4.96) ; 0.037$ \\
\hline Manifestations in CNS, n (\%) & $93(51.1)$ & $73(32.6)$ & 0.0001 & $0.878(0.433-1.778) ; 0.717$ \\
\hline - Encephalopathy & $47(37.6)$ & $35(22.6)$ & 0.006 & \\
\hline - Meningitis & $11(8.9)$ & $9(5.8)$ & 0.035 & \\
\hline - Brain abscess & 0 & $6(3.9)$ & 0.027 & \\
\hline - Embolic stroke & $37(29.6)$ & $29(18.7)$ & 0.033 & \\
\hline - Hemorrhagic stroke with no previous embolism & $14(11.3)$ & $8(5.2)$ & 0.059 & \\
\hline Renal embolism, n (\%) & $5(2.8)$ & $1(0.4)$ & 0.092 & \\
\hline Large vessel embolism, n (\%) & $13(7.3)$ & $18(8.1)$ & 0.775 & \\
\hline Spleen embolism, n (\%) & $11(6.2)$ & $16(7.2)$ & 0.693 & \\
\hline Kidney failure during IE $\left(^{* *}\right), \mathrm{n}(\%)$ & $94(52.2)$ & $6(33.9)$ & 0.0001 & $1.279(0.67-2.44) ; 0.455$ \\
\hline Heart failure, n (\%) & $109(60.2)$ & $75(33.8)$ & 0.0001 & $1.65(0.773-3.523) ; 0.1960 .846(0.312-$ \\
\hline Osteoarticular dissemination, n (\%) & $17(9.6)$ & $38(17.3)$ & 0.026 & $2.295) ; 0.743$ \\
\hline MRSA, n (\%) & $30(16.5)$ & $27(12.1)$ & 0.201 & \\
\hline Surgery performed, n (\%) & $50(27.5)$ & $82(36.6)$ & 0.051 & $1.778(0.299-10.592) ; 0.527$ \\
\hline Surgery indicated and conducted without delay, n (\%) & $42(23.1)$ & $81(36.2)$ & 0.004 & $0.242(0.041-1.426) ; 0.117$ \\
\hline $\begin{array}{l}\text { Surgery indicated and conducted with delay }>48 \mathrm{~h} \\
\text { in left ventricular failure, } \mathrm{n}(\%)\end{array}$ & $9(4.9)$ & $2(0.89)$ & 0.015 & \\
\hline Surgery indicated and not conducted, n (\%) & $30(16.5)$ & $11(4.9)$ & 0.0001 & $2.866(0.936-7.707) ; 0.066$ \\
\hline Early surgery < 2 weeks, n(\%) & $24(48)$ & $47(57.3)$ & 0.68 & \\
\hline EuroSCORE, median (IQR) & $13(9.5-16)$ & $9(7-12)$ & 0.0001 & $1.038(0.862-1.25) ; 0.692$ \\
\hline Logistic EuroSCORE, median (IQR) & $30.76(14.7-58.7)$ & $15.4(8.05-28.1)$ & 0.0001 & $1.033(0.997-1.069) ; 0.07$ \\
\hline Relapse, n (\%) & $5(2.7)$ & $9(4)$ & 0.480 & \\
\hline Reinfection, n (\%) & 0 & $6(2.6)$ & 1 & \\
\hline
\end{tabular}

$P^{*}:<0.05$ significant; $\mathrm{OR}, 95 \% \mathrm{Cl}$

Kidney failure ${ }^{*}$ (Creatinine $>1.5 \mathrm{~mL}$ or $25 \%$ increase versus baseline). Transplantation* (3 kidney, 1 heart, 1 bone marrow). Postponed: conducted $\geq 1$ month of hospitalization

37\% and identified a high Charlson index, congestive heart failure, CNS involvement, and sepsis/septic shock as risk factors [35].
With regard to the possible beneficial effect of early surgery in SA endocarditis, a meta-analysis reported a lower mortality rate when the surgery was conducted within the 
first 2 weeks rather than later in cases of native IE $(\mathrm{OR}=$ $0.46,95 \%$ CI $[0.31,0.69] ; p=0.001)$ but not in cases of prosthetic IE (OR $=0.83,95 \%$ CI $[0.65,1.06] ; p=0.413$ ) [37]. Another study found no reduction in one-year mortality in patients with $S$. aureus IE on prosthetic valve when the surgery was performed during the first 60 days of hospitalization rather than later (risk ratio, 0.67 [95\% CI: $0.39-1.15] ; p=0.15)$. The authors therefore recommended that surgery be considered on a case-by-case basis, regardless of whether SA is involved [38].

One study limitation is that our analysis considered data gathered over three decades rather than shorter time periods in order to obtain adequate statistical power. Strengths include the large patient sample and its prospective longitudinal multi-center design, involving specialist hospitals that formed a specific study group for this purpose. The results provide a reliable understanding of the current state of endocarditis in our region and may possibly be extrapolated to other regions of our country.

\section{Conclusion}

S. aureus endocarditis has a very high mortality rate in our setting. MRSA IE is associated with COPD, previous invasive procedure or recognized infection focus, and nosocomial or healthcare-related origin. Although methicillin resistance does not appear to have a decisive influence on the mortality risk, it may increase the therapeutic failure rate among patients receiving recommended treatments.

\section{Abbreviations \\ AICD: Automatic implantable cardioverter-defibrillator; CNS: Central nervous system; COPD: Chronic obstructive pulmonary disease; IE: Infective endocarditis; LVF: Left ventricular failure; MIC: Minimum inhibitory concentration; MRSA: Methicillin-resistant SA; MSSA: Methicillin -susceptible SA; SA: S. aureus}

\section{Acknowledgements}

The authors are grateful to the patients and professionals in the participating centers.

\section{Authors' contributions}

CHT, AA, JG, and FJMM contributed to the study design. CHT, JG, FJMM, APC, JDLTL, LELC, MN, JMR, DV, MVG, GO, RL, JL, JAL, AA provided substantial amounts of data and $\mathrm{CHT}$ and $\mathrm{AA}$ performed the statistical analysis. CHT, AA, an JML drafted the main manuscript and all authors interpreted the results. All authors reviewed and approved the final submitted manuscript.

\section{Funding}

The funders had no role in study design, data collection and analysis, decision to publish, or preparation of the manuscript.

\section{Availability of data and materials}

The dataset used and analyzed during the current study are not publicly available because this could result in identification of patients who gave interviews on the condition of anonymity. Data are available from the corresponding author on reasonable request for researches.

\section{Ethics approval and consent to participate}

All procedures followed were in accordance with the ethical standards. The study was approved by the current ethical committees of participant hospitals. This prospective cohort of patients with endocarditis was approved by the ethics committee (CEIC) of the original hospital that was launched by University Hospital "Virgen del Rocio", and subsequently by the other committees of participating Andalusian hospitals (CEIC of University Hospital "Virgen de las Nieves", Granada; CEIC of University Hospital "Virgen de la Macarena", Sevilla; CEIC of Hospital "Juan Ramón Jiménez", Huelva; CEIC of University Hospital, Regional "Carlos Haya", Málaga; CEIC of University Hospital "San Cecilio", Granada; and CEIC of University Hospital "Virgen de la Victoria", Málaga). These CEICs are integrated within the network of ethics Committes of Andalusian public health system (SSPA). CEICs are regulated by order/Decree 439/2010 December 14th of Andalusia. As it is an

observational, non-interventionist study, it was decided as appropriate to request the verbal consent of each of the patients and that it will be included in each of the subjects' medical records.

\section{Consent for publication}

All participants gave consent for publication.

\section{Competing interests}

The authors declare that they have no competing interests.

\section{Author details}

${ }^{1}$ Department of Infectious Diseases, Hospital Universitario Virgen de las Nieves, Av. de las Fuerzas Armadas n² 2, 18014 Granada, Spain. ${ }^{2}$ Infectious Disease Service, Hospital Universitario Virgen de la Macarena, Sevilla, Spain. ${ }^{3}$ Infectious Disease Service, Hospital Juan Ramón Jiménez, Huelva, Spain. ${ }^{4}$ Infectious Disease Service, Hospital Regional Universitario Carlos Haya, Málaga, Spain. ${ }^{5}$ nternal Medicine Service, Hospital Costa del Sol, Marbella, Spain. ${ }^{6}$ Infectious Disease Unit, Hospital Universitario San Cecilio, Granada, Spain. ${ }^{7}$ Infectious Disease Service, Hospital Universitario Virgen de la Victoria, Málaga, Spain. ${ }^{8}$ Infectious Disease Service, Hospital Universitario Virgen del Rocío, Sevilla, Spain. ${ }^{9}$ Infectious Disease Service, Oxford University Hospitals NHS Foundation Trust, Oxford, UK.

Received: 12 September 2019 Accepted: 17 February 2020

Published online: 21 February 2020

\section{References}

1. Hoen B, Duval X. Infective endocarditis. N Engl J Med. 2013;368:1425-33.

2. Truong VT, Ngo TMN, Bui QPV, Nguyen HC, Lê TTQ, et al. Microbiological profile and risk factors for inhospital mortality of infective endocarditis in tertiary care hospitals of South Vietnam. PLoS One. 2017;12:e0189421.

3. Tleyjeh IM, Abdel-Latif A, Rahbi H, et al. A systematic review of populationbased studies of infective endocarditis. Chest. 2007;132:1025-35.

4. Mostaghim AS, Lo HYA, Khardori N. A retrospective epidemiologic study to define risk factors, microbiology, and clinical outcomes of infective endocarditis in a large tertiary-care teaching hospital. SAGE Open Med. 2017;5:2050312117741772.

5. Gasch O, Camoez M, Domínguez MA, Padilla B, Pintado V, Almirante B, et al. Predictive factors for early mortality among patients with methicillinresistant Staphylococcus aureus bacteraemia. J Antimicrob Chemother. 2013; 68:1423-30.

6. Joo EJ, Park DA, Kang Cl, Chung DR, Song JH, Lee SM, et al. Reevaluation of the impact of methicillin-resistance on outcomes in patients with Staphylococcus aureus bacteremia and endocarditis. Korean I Intern Med. 2019;34:1347-62.

7. de Kraker ME, Wolkewitz M, Davey PG, Koller W, Berger J, Nagler J, et al. Clinical impact of antimicrobial resistance in European hospitals: excess mortality and length of hospital stay related to methicillin-resistant Staphylococcus aureus bloodstream infections. Antimicrob Agents Chemother. 2011;55:1598-605.

8. Rieg S, Peyerl-Hoffmann G, de With K, Theilacker C, Wagner D, Hübner J, et al. Mortality of $S$. aureus bacteremia and infectious diseases specialist consultation--a study of 521 patients in Germany. J Inf Secur. 2009;59:232-9.

9. Soriano A, Marco F, Martínez JA, Pisos E, Almela M, Dimova VP, et al. Influence of vancomycin minimum inhibitory concentration on the treatment of methicillin-resistant Staphylococcus aureus bacteremia. Clin Infect Dis. 2008:46:193-200.

10. van Hal SJ, Lodise TP, Paterson DL. The clinical significance of vancomycin minimum inhibitory concentration in Staphylococcus aureus infections: a systematic review and meta-analysis. Clin Infect Dis. 2012;54:755-71. 
11. Li JS, Sexton DJ, Mick N, Nettles R, Fowler VG Jr, Ryan T, et al. Proposed modifications to the Duke criteria for the diagnosis of infective endocarditis. Clin Infect Dis. 2000;30:633-8.

12. Charlson ME, Charlson RE, Paterson JC, Marinopoulos SS, Briggs WM Hollenberg JP. The Charlson comorbidity index is adapted to predict costs of chronic disease in primary care patients. J Clin Epidemiol. 2008;61:1234-40.

13. Dupuis JY, Feng W, Nathan H, Lam M, Grimes S, Bourkie M. The cardiac anesthesia risk evaluation score. Anesthesiology. 2001;94:194-204.

14. Higgins L. Quantifying risk and assessing outcome in cardiac surgery. J Cardiothorac Vasc Anesth. 1998;12:330-40.

15. Angus DC, Van der Poll T. Severe Sepsis and septic shock. N Engl J Med. 2013;369:840-51.

16. Almirante B, Miró JM. Infections associated with prosthetic heart valves, vascular prostheses, and cardiac pacemakers and defibrillators. Enferm Infecc Microbiol Clin. 2008;26:647-64.

17. Ben-Ami R, Giladi M, Carmeli Y, Orni-Was-serlauf R, Siegman-Igra Y, et al. Hospital-acquired infective endocarditis: should the definition be broadened? Clin Infect Dis. 2004;38:843-50.

18. Habib G, Lancellotti P, Antunes MJ, Bongiorni MG, Casalta JP, Del Zotti F, et al. The Task Force for management of infective endocarditis of the European society of cardiology). European Heart Journal. 2015;36:30753123.

19. Horstkotte D, Follath F, Gutschik E, Lengyel M, Oto A, Pavie A, et al. Task Force Members on Infective Endocarditis of the European Society of Cardiology; ESC Committee for Practice Guidelines (CPG); document reviewers guidelines on prevention, diagnosis and treatment of infective endocarditis executive summary; the task force on infective endocarditis of the European society of cardiology. Eur Heart J. 2004;25:267-76.

20. Nishimura RA, Carabello BA, Faxon DP, Freed MD, Lytle BW, O'Gara PT, et al. ACC/AHA 2008 guideline update on valvular heart disease: focused update on infective endocarditis: a report of the American College of Cardiology/ American Heart Association task force on practice guidelines endorsed by the Society of Cardiovascular Anesthesiologists, Society for Cardiovascular Angiography and Interventions, and Society of Thoracic Surgeons. J Am Coll Cardiol. 2008;52:676-85.

21. National Committee for Clinical Laboratory Standars. Methods for dilution antimicrobial susceptibility tests for bacteria that grow aerobically- fourth edition. Approved Standard. 1997;17:M7-A4.

22. Olmos A, Camarena JJ, Nogueira JM, Navarro JC, Risen J, Sánchez R. Application of an optimized and highly discriminatory method based on arbitrarily primed PCR for epidemiologic analysis of methicillin-resistant Staphylococcus aureus nosocomial infections. J Clin Microbiol. 1998;36:1128-34.

23. Freeman DH. Applied categorical data analysis. New York: Marcel Dekker; 1987.

24. Fernandez-Hidalgo N, Almirante B, Tornos P, Pigrau C, Sambola A, Igual A, et al. Contemporary epidemiology and prognosis of health care associated infective endocarditis. Clin Infect Dis. 2008;47:1287-97.

25. Perez de Isla L, Zamorano J, Lenine V, Váz-quez J, Ribera JM, Macaya C. Negative blood culture infective endocarditis in elderly: long-term followup. Gerontology. 2007;53:245-9.

26. Nagai T, Takase Y, Hamabe A, Tabata H. Observational Study of Infective Endocarditis at a Community-based Hospital: Dominance of Elderly Patients with Comorbidity. Intern Med. 2017. doi: 19. https://doi.org/10.2169/ internalmedicine.9274-17.

27. Asgeirsson $H$, Thalme A, Weiland O. Staphylococcus aureus bacteraemia and endocarditis - epidemiology and outcome: a review. Infect Dis (Lond). 2018; 50:175-92.

28. Sganga G, Tascini C, Sozio E, Carlini M, Chirletti P, Cortese F, et al. Focus on the prophylaxis, epidemiology and therapy of methicillin-resistant Staphylococcus aureus surgical site infections and a position paper on associated risk factors: the perspective of an Italian group of surgeons. World J Emerg Surg. 2016;11:26.

29. Aimonino Ricauda N, Tibaldi V, Leff B, Scarafiotti C, Marinello R, Zanocchi M, et al. Substitutive "hospital at home" versus inpatient care for elderly patients with exacerbations of chronic obstructive pulmonary disease: a prospective randomized, controlled trial. J Am Geriatr Soc. 2008:56:493-500.

30. Lodise TP, Graves J, Evans A, Graffunder E, Helmecke M, Lomaestro BM, et al. Relationship between vancomycin MIC and failure among patients with methicillin-resistant Staphylococcus aureus bacteremia treated with vancomycin. Antimicrob Agents Chemother. 2008;52:3315-20.

31. García de la Mària C, Cervera C, Pericàs JM, Castañeda X, Armero Y, Soy D, et al. Epidemiology and prognosis of coagulase-negative staphylococcal endocarditis: impact of vancomycin minimum inhibitory concentration. PLoS One. 2015:10:e0125818.

32. Cervera C, Castañeda X, de la Maria CG, del Rio A, Moreno A, Soy D, et al. Effect of vancomycin minimal inhibitory concentration on the outcome of methicillin-susceptible Staphylococcus aureus endocarditis. Clin Infect Dis. 2014:58:1668-75.

33. San-Juan R, Viedma E, Chaves F, Lalueza A, Fortún J, Loza E, et al. High MICs for Vancomycin and Daptomycin and complicated catheter-related bloodstream infections with methicillin-sensitive Staphylococcus aureus. Emerg Infect Dis. 2016;22:1057-66.

34. Aguado JM, San-Juan R, Lalueza A, Sanz F, Rodríguez-Otero J, GómezGonzalez C, et al. High vancomycin MIC and complicated methicillinsusceptible Staphylococcus aureus bacteremia. Emerg Infect Dis. 2011;17: 1099-102.

35. Fernández-Hidalgo N, Ribera A, Larrosa MN, Viedma E, Origüen J, de Alarcón A, et al. Impact of Staphylococcus aureus phenotype and genotype on the clinical characteristics and outcome of infective endocarditis. A multicentre, longitudinal, prospective, observational study. Clin Microbiol Infect. 2017; 18(17):30675-4

36. Pericàs JM, Messina JA, Garcia-de-la-Mària C, Park L, Sharma-Kuinkel BK, Marco F, et al. Influence of vancomycin minimum inhibitory concentration on the outcome of methicillin-susceptible Staphylococcus aureus left-sided infective endocarditis treated with antistaphylococcal $\beta$-lactam antibiotics: a prospective cohort study by the international collaboration on endocarditis. Clin Microbiol Infect. 2017;23:544-9.

37. Liang F, Song $B$, Liu R, Yang L, Tang H, Li Y. Optimal timing for early surgery in infective endocarditis: a meta-analysis. Interact Cardiovasc Thorac Surg. 2016;22:336-45.

38. Chirouze C, Alla F, Fowler VG Jr, Sexton DJ, Corey GR, Chu VH, et al. Impact of early valve surgery on outcome of Staphylococcus aureus prosthetic valve infective endocarditis: analysis in the international collaboration of endocarditis-prospective cohort study. Clin Infect Dis. 2015;60:741-9.

\section{Publisher's Note}

Springer Nature remains neutral with regard to jurisdictional claims in published maps and institutional affiliations.
Ready to submit your research? Choose BMC and benefit from:

- fast, convenient online submission

- thorough peer review by experienced researchers in your field

- rapid publication on acceptance

- support for research data, including large and complex data types

- gold Open Access which fosters wider collaboration and increased citations

- maximum visibility for your research: over 100M website views per year

At $\mathrm{BMC}$, research is always in progress.

Learn more biomedcentral.com/submission 